\title{
SIMVASTATIN-LOADED NANOCAPSULES REDUCE TNF-A EXPRESSION IN RAT PERITONEUM AFTER INFUSION OF PERITONEAL DIALYSIS SOLUTION
}

\author{
GILBERTO BARONI ${ }^{1 *}$, MYLENA FERNANDA FERRONATTO' ${ }^{1}$, GUILHERME DOS ANJOS CAMARGO², \\ AMANDA MARTINEZ LYRA ${ }^{2}$, PÉRICLES MARTIM RECHE ${ }^{1}$, JESSICA MENDES NADAL ${ }^{1}$, ANDRESSA NOVATSKI ${ }^{1}$, \\ LEANDRO CAVALCANTE LIPINSKI ${ }^{1}$, PAULO VITOR FARAG0 ${ }^{1}$
}

${ }^{1}$ Department of Medicine, State University of Ponta Grossa, Ponta Grossa, Parana, Brazil. ${ }^{2}$ Department of Pharmaceutical Sciences, State University of Ponta Grossa, Ponta Grossa, Parana, Brazil. Email: gbaroninefro@gmail.com

Received: 22 March 2021, Revised and Accepted: 05 May 2021

ABSTRACT

Objective: Obteinment and characterizing polymeric nanocapsules of simvastatin (SV), and investigating their action in an experimental model of peritoneal fibrosis induced in a rat by the infusion of peritoneal dialysis (PD) solution.

\begin{abstract}
Methods: Poly ( $\varepsilon$-caprolactone) nanocapsules containing SV (NC-SV) were prepared by interfacial deposition of a preformed polymer. A suspension of nanoparticles with no drug was prepared as negative control. The average particle size and polydispersity index were measured by photon correlation spectroscopy. The morphological and surface evaluation of prepared nanocapsules was performed using field emission scanning electron microscopy. The ultra-high performance liquid chromatography with photodiode array detection method was used to evaluate the drug encapsulation efficiency. The release profiles of SV from polymeric nanocapsules were obtained by dialysis diffusion technique. The Animal Study was performed in a total of 48 male Wistar rats (Rattus norvegicus) divided in four groups: Sham, PD group, SV group, and Simvastatin-loaded nanocapsules group (NC-SV). After 28 days, tissue samples were surgically removed from the abdominal to perform histological and immunohistochemistry analysis. The statistical analysis was performed by one-way ANOVA followed by Bonferroni test, or by Kruskal-Wallis.
\end{abstract}

Results: NC-SV presented suitable particle parameters with a mean particle size of $332 \mathrm{~nm}$, and an encapsulation efficiency of $99.87 \pm 0.46 \%$. The expression of tumor necrosis factor-alpha (TNF- $\alpha$ ) was significantly different in NC-SV group.

Conclusion: SV-loaded nanocapsules for controlled drug delivery were suitably prepared. This nanoformulation remarkable decreased the TNF- $\alpha$ tissue expression even at low SV dose in a chronic PD model.

Keywords: Chronic renal insufficiency, Encapsulating peritonitis, HMG-CoA reductase inhibitor, Interleukin-6, Nanotechnology, Peritoneal fibrosis, Tumor necrosis factor- $\alpha$.

(c) 2021 The Authors. Published by Innovare Academic Sciences Pvt Ltd. This is an open access article under the CC BY license (http://creativecommons.org/ licenses/by/4.0/) DOI: http://dx.doi.org/10.22159/ajpcr.2021v14i7.41562. Journal homepage: https://innovareacademics.in/journals/index.php/ajpcr

\section{INTRODUCTION}

The prevalence of chronic kidney disease (CKD) is increasing worldwide and reached 2204 patients per million inhabitants in the USA. Peritoneal dialysis (PD) is a procedure used in $7.1 \%$ and $5 \%$ of patients on renal replacement therapy in the USA [1] and in Europe [2], respectively. The main obstacles to the long-term PD treatment are both infections and pathological changes in the peritoneal membrane exposed to dialysis solutions (DS), which affect 50\% of PD patients. These patients may progress to the encapsulating peritonitis (EP) depending on the treatment time interval [3]. The risk of EP is significantly increased with PD treatment longer than 10 years ( $>10 \pm 12$ years vs. $>6 \pm 8$ years, OR: 5.5 ). In addition, EP is a disease with high mortality, which reaches $74 \%$ in patients with severe forms [4]. It can also occur in children on PD, showing a similar prevalence to adults $[5,6]$. The symptoms onset may occur during PD. However, they may also occur very late, even after kidney transplantation $[7,8]$. In addition, when analyzing studies about the prevalence of EP, we have to take into account the diagnosis of this condition does not include a screening test to detect mild or asymptomatic cases, which explains the cases diagnosed years after the PD ending [9]. Therefore, the current prevalence of EP may be higher than that reported.

The pathophysiology of EP is complex. Factors that trigger the process are the exposure of peritoneal membrane to DS, bacterial infections, and inflammatory condition by uremia itself. Several mediators are involved, including cytokines [10]. Regardless of PD, uremia causes damage to the peritoneum. The carbonyl products formation occurs due to uremia, in addition to an accelerating production of advanced glycation end products. However, the PD onset also involves injury caused by catheter used and DS. This inflammatory condition could generate the peritoneum fibrosis and EP [11].

Simvastatin (SV) is a competitive reversible inhibitor of a natural substrate of hydroxymethylglutaryl coenzyme A reductase and the use of statins to prevent cardiovascular risk is well established. Its prescription depends on the analysis of cardiovascular risk of each patient. Patients with CKD are in the high-risk group; therefore, the prescription of statins is widely indicated to them [12]. Besides the lipid-lowering action, pleiotropic actions of statins have been described. These actions can contribute to a reduction of cardiovascular events in patients using statins. Statins inhibit the synthesis of isoprenoids, such as farnesyl pyrophosphate and geranyl pyrophosphate, also they inhibited the prenylation of specific proteins, such as Rho and Ras, which act through nuclear factor- $\mathrm{KB}(\mathrm{NF}-\kappa \mathrm{B})$, which is involved in the processes: Inflammation, proliferation and apoptosis, and it is implicated in atherogenesis. Statin treatment results in increased eNOS activity by reducing Rho prenylation. Statins also reduce the concentration of caveolin-1, which is the inhibitor partner of calmodulin and increases the affinity of binding of eNOS to calmodulin. Negative regulation of NF- KB pathway also leads to an increase in eNOS activity [13].

By these actions, statins have been used in several disease models, including their use in preventing peritoneal fibrosis. In a previous 
study from our research group, Baroni et al. used the DS infusion model through daily puncture of the peritoneum to evaluate the influence of $\mathrm{SV}$ on fibrosis induced by DS in Wistar rats. Two groups of animals were subjected to a daily infusion of a $4.25 \%$ DS by intraperitoneal injection. One group received daily SV at a dose of $4 \mathrm{mg} / \mathrm{kg}$, and the control group did not receive the drug. No effect was found on the use of SV, perhaps due to the low drug bioavailability [14].

Yeniçerioglu et al. studied the effect of atorvastatin in non-uremic Wistar rats. They were randomized in three groups: Sham (intraperitoneal saline), PD (PD 3.86\% intraperitoneal dextrose-containing DS), and treatment (TX, 3.86\% intraperitoneal dextrose containing DS plus atorvastatin added to drinking water at a dose of $80 \mathrm{mg} / \mathrm{mL}$ ). The main findings were greater inflammation, fibrosis, and vascular proliferation in the PD group than in the Sham group. These features seemed to decrease significantly when atorvastatin was used as TX [15].

To evaluate the effect of SV on the mesenchymal epithelial transition action, Chang et al. carried one study in two parts. In vitro: Human peritoneal mesothelial cells (HPMCs) were exposed to $5.6 \mathrm{mmol} / \mathrm{L}$ glucose (NG) or $100 \mathrm{mmol} / \mathrm{L}$ glucose (HG) with or without SV at $1 \mathrm{mmol} / \mathrm{L}$ concentration. In vivo: 32 Sprague-Dawley rats were submitted to PD catheters with saline (C, $\mathrm{n}=16)$ or $4.25 \%$ PD fluid (PD, $\mathrm{n}=16$ ) for 4 weeks. SV intraperitoneally treatment ( $5 \mathrm{mg} / \mathrm{kg} /$ day) were applied to eight rats from each group. E-cadherin expression presented a significant decrease when compared to NG cells, while fibronectin expression, a-SMA, Snail were significantly increased in HPMCs submitted to $\mathrm{HG}$, all these changes were repealed by $S V(p<0.05)$ [16].

Yang et al. carried out a study in rats, comparing a group which used SV $(10 \mathrm{~mol} / \mathrm{L})$ with a group without SV, divided in a subgroup that used troglitazone $(50 \mathrm{~mol} / \mathrm{L})$ and one that did not. Cholesterol and oxidized LDL (ox-LDL) content was measured in macrophages. The content of IL-6 and tumor necrosis factor-alpha (TNF- $\alpha$ ) in macrophages was measured, as well as the expression of IL- 6 and TNF- $\alpha$ mRNA. It was demonstrated that macrophages exposed to ox-LDL had an increase in cholesterol content and foam cells appeared, an effect normally reversed by use of SV. The use of troglitazone abolished this effect [17]. Kim et al. showed that the presence of SV reduces the expression of IL-6 and IL-8 in an in vitro study, as well as reduces the expression of reactive oxygen species in cells isolated from intestinal cells stimulated by TNF- $\alpha$. The same group, in a study model of intestinal ulceration in vivo, inducing lesions by anti-inflammatory drugs, demonstrated that the use of $\mathrm{SV}$ reduced the expression of reactive oxygen species, as well as the number of intestinal ulcerations [18].

None of papers briefly mentioned above used nanotechnology to optimize the drug effect. At present, one of the biggest challenges of the pharmaceutical industry is developing drugs with maximum of their therapeutic effect and reduction of their adverse effects [19], since approximately $40 \%$ of the discovered substances are left aside, mainly because of their low solubility and bioavailability [20]. To overcome these problems, the use of nanotechnology has altered the panorama of the pharmaceutical industries by enabling the development of safer and more effective drugs, with better biocompatibility and taking advantage of all their action potential [21].

SV is a lactone prodrug, which is modified in the liver. SV is a white, crystalline, and non-hygroscopic powder with $\log \mathrm{p}=4.4$. It is practically insoluble in water $(30 \mu \mathrm{g} / \mathrm{mL})$ and $0.1 \mathrm{~mol} / \mathrm{L} \mathrm{HCl}(60 \mu \mathrm{g} / \mathrm{mL})$. Due to its very low aqueous solubility, SV exhibits controlled absorption by dissolution and, therefore, shows reduced absorption, distribution and arrival at the target organ. Various procedures can be used to improve SV solubility by enhancing its bioavailability as inclusion complex, solid dispersion, surfactant solubilization, and particle reduction techniques [22]. Therefore, nanotechnology can significantly improve the drug effects by creating new SV-loaded formulations.

The objective of this study was to develop and characterize SV-loaded nanocapsules and compare with pure drug and its effect on peritoneal fibrosis and on expression of TNF- $\alpha$ and IL- 6 induced by the use of $4.25 \%$ DS

\section{METHODS}

Preparation of polymeric nanocapsules

Poly ( $\varepsilon$-caprolactone) (PCL) nanocapsules containing simvastatin (NC-SV) were prepared by interfacial deposition of a preformed polymer [23]. Briefly, $100 \mathrm{mg}$ of PCL (Mw 14,000 g/mol, Sigma-Aldrich, St. Louis, MO, USA) was solvated in acetone $(27 \mathrm{~mL})$ in the presence of sorbitan monostearate (Span ${ }^{\circledR} 60,77 \mathrm{mg}$ ), triglycerides of capric/ caprylic acids (MCT, $300 \mathrm{mg}$ ), and SV (SV, $200 \mathrm{mg}$, Mw $418.57 \mathrm{~g} / \mathrm{mol}$, lot DK40-1506061, certified by Galena Farmacêutica, Campinas, Brazil). This organic phase was then dripped slowly into the aqueous phase containing water $(53 \mathrm{~mL})$ and polysorbate 80 (Tween $^{\circledR} 80,77 \mathrm{mg}$ ), previously prepared and maintained under vigorous magnetic stirring at $40^{\circ} \mathrm{C}$. The magnetic stirring was kept for another $10 \mathrm{~min}$ after the end of the dripping and the solvent was eliminated using a rotary evaporator (FISATOM, model 801, Diadema, Brazil), reaching a final volume of $10 \mathrm{~mL}$ and drug concentration of $20 \mathrm{mg} / \mathrm{mL}$. This formulation was obtained in triplicate from three different batches. A suspension of nanoparticles with no drug (NC-N) was prepared as negative control.

\section{Characterization of polymeric nanocapsules}

The average particle size and polydispersity index (PDI) $(n=3)$ were measured by photon correlation spectroscopy (Zetasizer Nanoseries, Malvern Instruments, Malvern, UK) after diluting each sample in ultrapure water $(1: 500, v / v)$. At the same equipment and using the same sample preparation, zeta potential $(\mathrm{n}=3)$ was determined by electrophoretic mobility technique.

The morphological and surface evaluation of prepared nanocapsules was performed using field emission scanning electron microscopy (FESEM) (Tescan, model Mira 3, Brno, Czech Republic). The samples were previously submitted to metallization with gold in an IC-50 Ion Coater metallizer (Shimadzu, Kyoto, Japan). An acceleration voltage of 8-10 kV was used to obtain electromicrographs.

The ultra-high performance liquid chromatography with photodiode array detection (UHPLC-DAD) method was used for evaluate the drug encapsulation efficiency using a previously validated analytical method [24] with modifications. In brief, suspension of nanocapsules was submitted to a combined ultrafiltration/centrifugation using centrifugal devices (Amicon ${ }^{\circledR}$ 10,000 NMWL, Millipore, Bedford, MA, USA) at $2200 \mathrm{~g}$ during $30 \mathrm{~min}$ in triplicate. Free SV was determined in ultrafiltrate using an UHPLC method in Nexera X2 equipment (Shimadzu, Kyoto, Japan). The UHPLC system was equipped with a column oven compartment (model CTO-20AC), an on-line degasser (model DGU-20A5RA), a quaternary pump (model LC-30AD), an auto sampler (model SIL-30 AC), a communication bus module (model CBM-20A), and a photodiode array wavelength detector (model SPDM20A). Data acquisition, analysis, and reporting were performed using LabSolutions ${ }^{\circledR}$ chromatography software (Shimadzu, Milton Keynes, UK, version 5.73). Chromatographic separation was accomplished using a Shimadzu Shim-pack XR-ODS III C18 analytical column (Kyoto, Japan) with $2.2 \mu \mathrm{m}$ particle size, $2.0 \mathrm{~mm}$ internal diameter at temperature of $40 \pm 2^{\circ} \mathrm{C}$ using UV detection at $237 \mathrm{~nm}$. The isocratic mobile phase consisted of acetonitrile: water acidified with phosphoric acid (83:17, $\mathrm{v} / \mathrm{v}$ ) at a flow rate of $0.75 \mathrm{~mL} / \mathrm{min}$. The encapsulation efficiency (EE, \%) was calculated using Eq. (1).

$$
\mathrm{EE}(\%)=\frac{\text { Theoreticaldrugloading }- \text { Freedrugcontent }}{\text { Theoreticaldrugloading }} \times 100
$$

\section{In vitro drug release study}

The release profiles of SV from polymeric nanocapsules were obtained by dialysis diffusion technique. Each sample $30 \%$ ethanol-water solution of SV and NC-SV) was placed into a dialysis bag (Spectra/ Por $^{\circledR}$ molecular porous membrane tubing, MWCO 10,000, Spectrum 
Laboratories, Rancho Dominguez, CA, USA) at an equivalent concentration of $1 \mathrm{mg} / \mathrm{mL}$ and a final volume of $3 \mathrm{~mL}$. This system was then immersed in $500 \mathrm{~mL}$ of water with $30 \%$ of ethanol at $37^{\circ} \mathrm{C}$ and kept under continuous magnetic stirring of $50 \mathrm{rpm}$. Aliquots of $5 \mathrm{~mL}$ were withdrawn at predetermined time intervals and replaced by the same volume of fresh medium. The amount of SV released was assayed by the aforementioned UHPLC-DAD method. The experiment was performed in triplicate from three independent batches.

\section{Animal study}

The in vivo study was submitted to the Animal Ethics Committee from State University of Ponta Grossa (UEPG) and approved under number 37/2018. A total of 48 male Wistar rats (Rattus norvegicus) weighting from 200 to $250 \mathrm{~g}$ were obtained from the Animal House Facility at the UEPG, Faculty of Medicine. The animals were fed a standard rat pellet diet and it was allowed free access to water. The rats were kept in labeled cages with a maximum of five animals per cage at $25 \pm 2^{\circ} \mathrm{C}$ and 12-h light/dark cycle.

The intraperitoneal injection model was performed for induction of peritoneal fibrosis. A DS with glucose at $4.25 \%$ buffered with lactate (Baxter Hospitalar, São Paulo, Brazil) was intraperitoneally injected using a $25 \times 7 / 8$ " needle. There were four experimental groups, divided as follows: Group 1 (Sham), 12 animals submitted to the daily repeated puncture for 28 days with no solution infusion; Group 2 (PD group), 12 animals subjected to the daily peritoneal puncture for 28 days with DS infusion at a dose of $10 \mathrm{~mL} / 100 \mathrm{~g}$ of weight; and Group 3 (SV group), 12 animals submitted to the daily repeated puncture for 28 days with DS infusion at $10 \mathrm{~mL} / 100 \mathrm{~g}$ of animal weight. This group also received $4 \mathrm{mg} /$ kg of SV per gavage daily during 28 days. Group 4 (SV-loaded nanocapsules group - NC-SV), 12 animals submitted to the daily peritoneal puncture for 28 days with DS infusion at $10 \mathrm{~mL} / 100 \mathrm{~g}$ of weight. This group received $\mathrm{NC}-\mathrm{SV}$ containing $4 \mathrm{mg} / \mathrm{kg}$ of SV per gavage daily.

After 28 days, the animals were slaughtered and $1-\mathrm{cm}^{2}$ tissue samples were surgically removed from the abdominal wall of the upper right quadrant as far as possible from the puncture point. After the routine paraffin embedding, 4- $\mu \mathrm{m}$ thick sections were stained with hematoxylin and eosin and Sirius red (SR). Ten histological fields were chosen and ten peritoneum thickness measurements were taken in each field using the Axio Scan.Z1 digital slide scanner (Carl Zeiss Microscopy, Jena, Germany). The amount of collagen types I and III, in percentage per high power field (HPF), was automatically measured using SR staining with the Axio Scope.A1 polarized light microscope (Carl Zeiss Microscopy, Jena, Germany).

For immunohistochemistry, the 4- $\mu \mathrm{m}$ thick sections were rehydrated in decreasing ethanol concentration and incubated in 5\% hydrogen peroxide and methanol. These samples were then immersed in ImmunnoRetrivier ${ }^{\circledR}$ (Dako, Carpinteria, CA, USA), followed by incubation in diluted solution of antibodies anti-TNF- $\alpha$ (ab6671, 1:100, Abcam ${ }^{\circledR}$, Cambridge, UK) and anti-IL-6 (ab9324, 1:400, Abcam ${ }^{\circledR}$, Cambridge, UK) at $4{ }^{\circ} \mathrm{C}$. Then, the reaction was carried out using 3-3'-diaminobenzidine chromogen solution (code D7679, Sigma-Aldrich, St. Louis, MO, USA), followed by the staining with Harris' hematoxylin solution (Biotec, Lages, Brazil), the ethanol dehydration process, and the clearing using xylene. The slides were observed using the Axio Scan.Z1 digital slide scanner and the ZEN 2.3 program (Carl Zeiss Microscopy, Göttingen, Germany) concerning to the presence/absence of TNF- $\alpha$ and IL6inpercentage per HPF of peritoneal samples.

The statistical analysis was performed by one-way ANOVA, followed by Bonferroni test, except for results of TNF- $\alpha$, in which the Kruskal-Wallis test was used. $\mathrm{p}<0.05$ was considered statistically significant.

\section{RESULTS}

Preparation and characterization of polymeric nanocapsules SV-loaded PCL nanocapsules (NC-SV) and non-loaded PCL nanocapsules (NC-N) suspensions showed a uniform milky white appearance and atypical opalescent bluish reflection. NC-SV presented suitable particle parameters for oral use as mean particle size of $332 \mathrm{~nm}$, PDI of 0.290 , and zeta potential of $-58.7 \mathrm{mV}$.

Nanoscale dimensions were registered for NC-SV (a) and NC-N (b) when their images were assessed by FESEM (Fig. 1). NCs were spherically shaped and had smooth surface with uniform distribution. In addition, no drug crystals were seen on their surfaces.

The proposed UHPLC-DAD method was used for determining the drugloading efficiency. Fig. 2 depicts the chromatograms obtained for SVloaded (a) and non-loaded (b) nanocapsules. SV showed an appropriate separation at short retention time of $1.71 \mathrm{~min}$.

Comparing both chromatograms, the other formulation components demonstrated no interference in drug quantification. Considering all the chromatographic data, a high encapsulation efficiency of $99.87 \pm 0.46 \%$ was achieved for NC-SV.

\section{In vitro drug release study}

The SV release profiles as pure drug and nanoformulation (NC-SV) are reported in Fig. 3. The free SV showed a rapid drug release profile by reaching a mean release value of $80 \%$ after $148 \mathrm{~min}$ of the experiment.
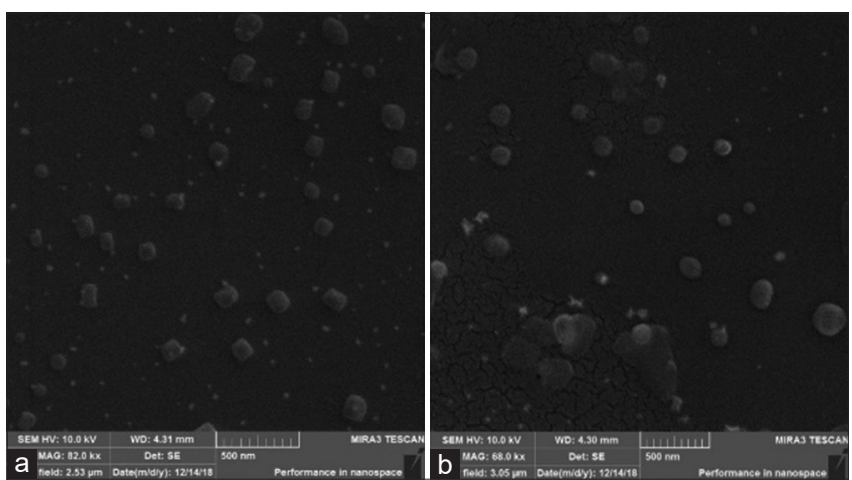

Fig. 1: Photomicrographs of simvastatin-loaded and non-loaded nanocapsules observed by FESEM: (a) NC-SV

(68 k× magnification) and (b) NC-N (82 k× magnification)

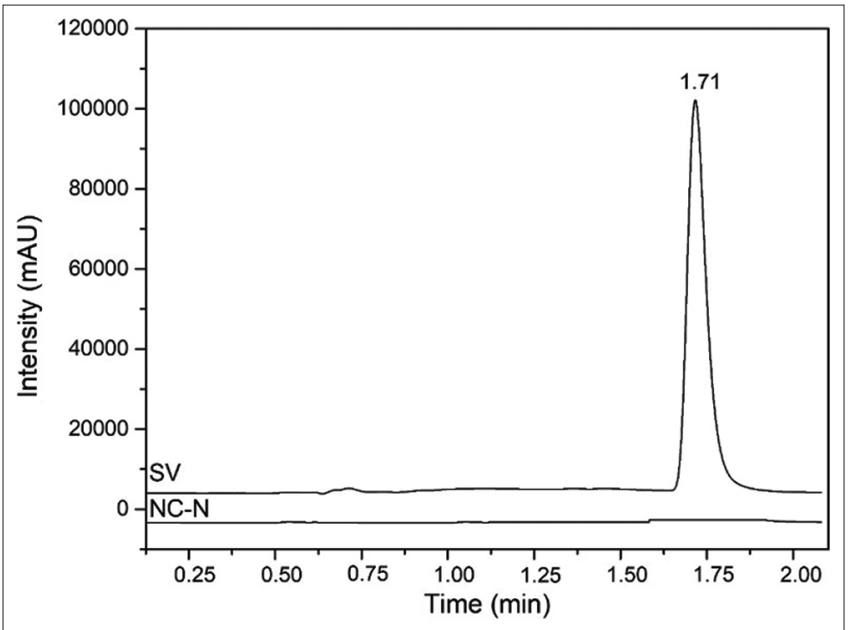

Fig. 2: UHPLC-DAD chromatograms obtained for simvastatinloaded (a) and non-loaded (b) nanocapsules. Chromatographic conditions:isocratic elution mode; mobile phase: acetonitrile:water acidified with phosphoric acid (pH 3.0) (83:17, $\mathrm{v} / \mathrm{v}$ ); flow rate: $0.75 \mathrm{~mL} / \mathrm{min}$; UV detection wavelength: $237 \mathrm{~nm}$; column temperature: $40 \pm 2^{\circ} \mathrm{C}$; run time: $2.11 \mathrm{~min}$; and retention time: $1.71 \mathrm{~min}$ 
The NC-SV formulation released $80 \% \mathrm{SV}$ at $2880 \mathrm{~min}$ ( $48 \mathrm{~h}$ ). Therefore, the SV-loaded nanocapsules demonstrated a prolonged release profile with no burst effect, when compared with pure drug.

\section{Animal study}

The results of histological analysis are summarized in Table 1. In brief, no statistically significant difference was observed for peritoneal thickness when experimental groups were compared. However, a significant increase in the inflammation-associated collagen type III was achieved for PD group $(\mathrm{p}<0.001)$ when compared with Sham group. The SV group also presented a statistical difference in collagen type III expression comparing with Sham group ( $\mathrm{p}<0.001)$, while the effect of NC-SV concerning to collagen type III was statistically similar $(p>0.05)$ to the Sham group. The nanoformulation also revealed a statistical difference in collagen type III when compared with other experimental groups, PD group $(p<0.001)$ and SV group $(p<0.05)$. The same statistical significance was obtained to a usual collagen type I considering the studied groups due to its complementary nature in total collagen amount to reach $100 \%$

The results of TNF- $\alpha$ tissue expression in the peritoneal samples are depicted in Fig. 4. The TNF- $\alpha$ tissue expression was $23.5 \pm 14.5 \%$,

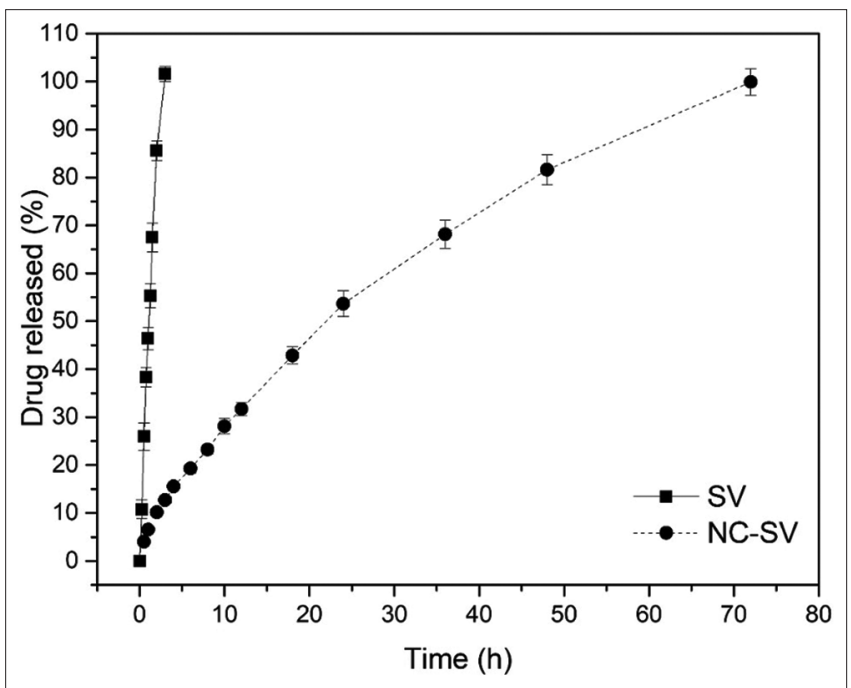

Fig. 3: In vitro drug release profiles of free simvastatin (SV) and simvastatin-loaded nanocapsules (NC-SV) using $30 \%$ ethanolwater solution as dissolution medium

Table 1: Peritoneum thickness and collagen amount in the experimental groups submitted to the chronic use of $4.25 \%$ DS for 28 days

\begin{tabular}{|c|c|c|c|c|}
\hline \multirow[t]{2}{*}{ Parameters } & \multicolumn{4}{|c|}{ Experimental groups } \\
\hline & SHAM & PD & SV & NC-SV \\
\hline Thickness* $(\mu \mathrm{m})$ & $19.1 \pm 6.0$ & $20.1 \pm 4.9$ & $19.2 \pm 6.1$ & $25.5 \pm 9.1$ \\
\hline $\begin{array}{l}\text { Collagen type I* } \\
(\% / \mathrm{HPF})\end{array}$ & $82.9 \pm 7.8$ & $77.2 \pm 12.4$ & $56.8 \pm 13.6$ & $79.6 \pm 8.1$ \\
\hline $\begin{array}{l}\text { Collagen type III* } \\
\text { (\%/HPF) }\end{array}$ & $17.1 \pm 7.8$ & $22.8 \pm 12.4$ & $43.2 \pm 13.6$ & $20.4 \pm 8.1$ \\
\hline $\begin{array}{l}\text { Collagen ratio } \\
\text { type I: III }\end{array}$ & $4.85: 1$ & $3.38: 1$ & $1.31: 1$ & $3.96: 1$ \\
\hline $\begin{array}{l}\text { Increase in } \\
\text { collagen type III } \\
\text { expression** }\end{array}$ & - & $\begin{array}{l}\uparrow 1.33 \text { fold } \\
(+33 \%)\end{array}$ & $\begin{array}{l}\uparrow 2.53 \text { fold } \\
(+153 \%)\end{array}$ & $\begin{array}{l}\uparrow 1.19 \text { fold } \\
(+19 \%)\end{array}$ \\
\hline
\end{tabular}

*Values are depicted as mean \pm standard deviation, **Significant differences occur in the Collagen I: III ratio in Group SV when compared to the others. DS: Dialysis solutions, PD: Peritoneal dialysis, SV: Simvastatin, NC-SV: Nanocapsules containing simvastatin, HPF: High power field
$20.3 \pm 11.1 \%$, and $0.79 \pm 0.76 \%$ (HPF) for PD and SV an NC-SV groups, respectively.

No statistical difference was observed between PD and SV groups. However, a statistically significant decrease in TNF- $\alpha$ tissue expression was achieved when NC-SV group was compared with PD $(\mathrm{p}<0.0002)$ and $\mathrm{SV}(\mathrm{p}<0.0002)$ groups.

The immunohistochemical images for TNF- $\alpha$ expression in the peritoneal tissue of rats are shown in Fig. 5. TNF- $\alpha$ immunoslides indicated that the TNF- $\alpha$ protein expression (\%/HPF) was significantly higher in the peritoneal section obtained from PD and SV groups (Fig. $5 \mathrm{a}$ and $\mathrm{b}$ ). Nanoformulation treatment containing simvastatin (NC-SV group) prevented the increase in peritoneal tissue expression of TNF- $\alpha$ (Fig. 5c).

Concerting to the IL-6, the tissue expression was $3.14 \pm 1.35 \%$, $2.72 \pm 1.28 \%$, and $2.62 \pm 1.32 \%$ (HPF) for PD, SV, and NC-SV groups, respectively. No statistically significant difference was observed between paired groups.

\section{DISCUSSION}

In this study, SV-loaded nanocapsules were successfully obtained as nanosuspensions by the interfacial deposition of preformed polymer. This formulation presented a final opalescent bluish aspect due to the Tyndall effect from colloids $[23,25]$. The mean particle size and PDI value were similar to those previously recorded by photon correlation spectroscopy for other polymeric nanocapsules [26]. PDI values close to zero are considered monodisperse and $>0.5$ indicate heterogeneous dispersion [23]. Zeta potential was also suitable since it was higher than $|30 \mathrm{mV}|$, which is usually considered having sufficient repulsive force to achieve better physical colloidal stability [25]. The electron micrographs confirmed the spherical shape and the smooth surface, which are typical to polymeric nanocapsules, obtained using PCL as polymer [27]. Hence, the nanoformulation containing SV showed all required features in terms of size, superficial charge, and morphology for its use by oral, intraperitoneal, and intravenous routes.

However, it is essential to investigate the encapsulation efficiency to discover the total drug entrapped within the colloidal nanoformulation after its preparation and to use corresponding drug amount in animal studies. SV-loaded PCL nanocapsules (NC-SV) had encapsulation efficiency near to $100 \%$. This result is better than that one made by Gambhire et al., who obtained SV-loaded solid lipid nanoparticles by pre-emulsion followed by the ultrasonication with an encapsulation efficiency of $72.52 \%$ [28]. It was also slightly better than the result achieved by Zhang $e t$ al., who prepared lipid nanoparticles by emulsionsolvent evaporation and achieved encapsulation efficiencies from $97.2 \%$ to $99.2 \%$ [29]. Shinde and More studied poly (lactic-co-glycolic acid) nanoparticles obtained by nanoprecipitation and recorded encapsulation efficiencies between $87.03 \%$ and $97.18 \%$ [30]. These high values of encapsulation efficiency are mainly due to the poor aqueous solubility of SV, which provides a high drug entrapment in oil/ lipid-based formulations [29].

The next stage was to investigate the in vitro drug release in order to confirm if nanoformulation could provide a controlled-release pattern. A typical structure of an oily core surrounded by a polymeric shell was strategically planned for this purpose to avoid the immediate release of SV and to obtain a prolonged response. This approach was crucial to avoid the administration of multiple doses per day on rats and ensuring a longer-lasting pharmacological effect than free drug. Our nanoformulation containing SV proved a prolonged release of the drug during $48 \mathrm{~h}$ with no relevant initial burst. Fathi et al. [31] prepared lipid nanoparticles through emulsification-solvent evaporation followed by ultrasonication and reported an initial rapid release of SV using dialysisspectrophotometry, which was proportional to the oleic acid and the surfactant content, followed by a prolonged release for $24 \mathrm{~h}$. Therefore, the formulation NC-SV can provide a controlled-release pattern for SV 


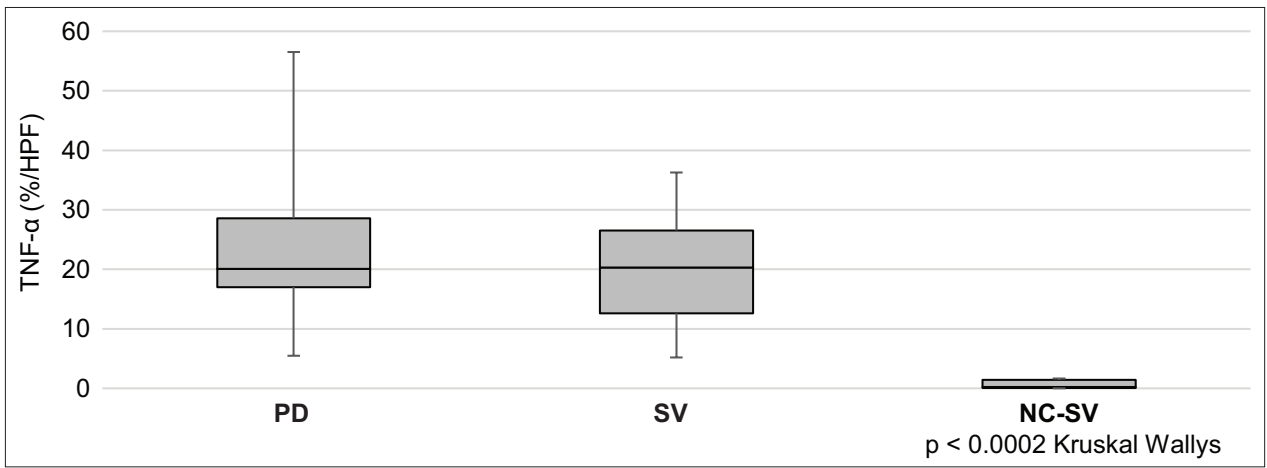

Fig. 4: Tumor necrosis factor-alpha (TNF- $\alpha$ ) tissue expression (percentage per high power field) in the peritoneal samples of rats treated with peritoneal dialysis solutions (PD), simvastatin (SV), and simvastatin-loaded nanocapsules (NC-SV)

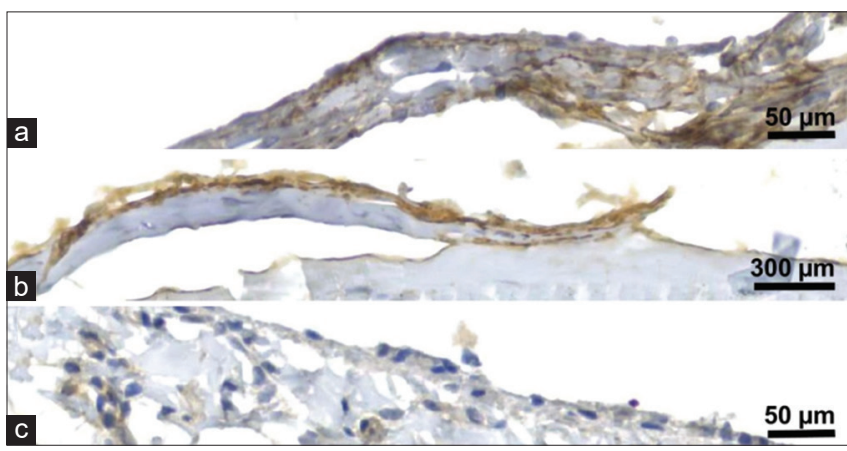

Fig. 5: Results of tumor necrosis factor-alpha (TNF- $\alpha$ ) immunoexpression in the experimental groups, where the brown precipitate indicates the presence of the target antigen. TNF- $\alpha$ level was high in the peritoneal tissue slices of peritoneal dialysis rats (a), markedly present in the peritoneal tissue of simvastatin group (b), but not in rats treated with NC-SV (c). Several microphotographs were taken using a $\times 10-100$ magnification objective and the images are representative of the experimental results

and can ensure a better pharmacokinetics since this nanocarrier can also avoid the SV extensive metabolism by cytochrome-3A system in gut and liver [29].

Regarding to the animal study, SV and NC-SV groups did not decrease the peritoneum thickness as expected. These results may be associated with the low dose of SV used (only $4 \mathrm{mg} / \mathrm{kg}$ ) as free drug and in the SV-loaded nanocapsules. Rats can support very high doses of SV [32]. Besides that, a previous animal study involving the administration of SV at $25 \mathrm{mg} / \mathrm{kg}$ did not observe changes in bone tissue, after ovariectomy, or in bone healing of rats [33]. However, the use of atorvastatin added into drinking water at a dose of $80 \mathrm{mg} / \mathrm{mL}$ provided significant minor fibrosis and thinner peritoneum [15]. In general, Wistar rats usually drink $20-50 \mathrm{~mL}$ water a day $(10 \mathrm{~mL} / 100 \mathrm{~g}$ body weight/day) [34]. Hence, high doses of atorvastatin reaching above $1.6 \mathrm{~g} /$ day were used for achieving morphological changes in peritoneum thickness of rats. In this sense, we assume that low dose of SV used was accountable for the lack of effects on the peritoneal thickness of Wistar rats in the SV and NC-SV groups.

When the type of collagen was evaluated, the NC-SV group showed an expression of type III collagen statistically similar to sham and DP. Therefore, nanoformulation was able to reduce type III collagen associated with inflammation in order to control levels. Type III collagen is secreted by fibroblasts and other types of mesenchymal cells, making it an important element in several diseases associated with inflammation, such as renal fibrosis [35]. Consequently, the low expression of type III collagen provides strong evidence that inflammation has been significantly suppressed by nanoformulation, which was not so remarkable with the use of free SV, although the anti-inflammatory effect of SV is well known to inhibit formation of intracellular isoprenoids and improve the bioavailability of NO [12].

The reason of DP group was not significantly different from the sham which is not very clear. One possible explanation is due to the different manipulation between these groups, since the sham group was not subjected to gavage. It is known that damage to the esophageal mucosa caused by gavage can alter the cells of intestinal epithelium. The damage of esophageal epithelium causes a reduction in $\gamma \delta \mathrm{T}$ cells, which, in turn, plays an important regulatory role in maintaining the function of intestinal epithelium barrier and its cell renewal. The reduction in $\gamma \delta \mathrm{T}$ cells can also cause a reduction in CD3+ cells. This study provides initial evidence of the importance of esophageal integrity and intestinal cell populations and that the use of prolonged and repeated gavage can be accompanied by immunological complications [36].

Recently, it has been discovered that not only do these $\gamma \delta \mathrm{T}$ cells provide essential epithelial growth factors, which are crucial for maintaining tissue homeostasis and timely return to steady-state after damage, but they also act quickly to compartmentalize and limit microbial pathogenic exposure to the systemic immune compartment [37]. We can hypothesize that animals submitted to repeated gavage may have had a more intense inflammatory reaction. Anyway, in the NC-SV group, which was also subjected to gavage, the pattern of proportion between types I and III collagen was similar to that of sham. This could be explained by the more intense anti-inflammatory action of this formulation.

Considering the promising results obtained for the NC-SV group during the collagen analysis, the investigation was deepened to verify which inflammatory cytokines was inhibited. The nanoformulation decreased expressively the TNF- $\alpha$ level expression in peritoneal tissue of rats, what was not observed for free SV. TNF- $\alpha$ plays a key role in many inflammatory diseases. It is produced by macrophages, natural killer cells, neutrophils, and several non-hematopoietic cells. Although TNF- $\alpha$ was initially identified by its cytotoxicity against certain cell lines, its primary function (associated with IL-1) is to initiate the cascade of factors associated with inflammatory response. Therefore, it seems like the nanoformulation was able to improve the drug amount in peritoneal tissue and also ensuring the suitable anti-inflammatory effect of SV at low dose against the inflammatory status provided by the PD procedure. Some previous reports demonstrated the higher intestinal permeability and the increased bioavailability when nanosystems were used as technological approaches for SV [31,38]. Moreover, a significant reduction in inflammatory cytokines, including TNF- $\alpha$ and IL-6, was observed in other animal study involving intestinal ischemia in rats and SV at a dose of $20 \mathrm{mg} / \mathrm{kg}$ [39]. In that sense, the anti-inflammatory effect provided by the NC-SV can be associated with an increase of collagen type III expression and a significant reduction 
of TNF- $\alpha$ expression when the experimental rat model of peritoneal fibrosis induced by infusion of PD solution was used.

Considering the reduction of IL-6 by SV in vascular smooth muscle cells and macrophages was previously reported [37], this cytokine expression was also investigated. However, IL-6 levels were similar among the PD, SV, and NC-SV groups. Kishimoto [41] proposed that IL-6 is a multifunctional cytokine involved in cell proliferation and differentiation, maintaining immune homeostasis, macrophage function, and other key functions. IL-6, acting through the latent transcription factors signal transducer and activator of transcription-3 (STAT3) and STAT1, also plays pivotal roles in governing leukocyte infiltration during acute inflammation [42]. In this present study, no significant change in the IL- 6 tissue expression was found for pure SV and SV-loaded nanoformulation. The possible reason may be that IL-6 is an acute pro-inflammatory mediator and the animal model involved the chronic and long-lasting use of $4.25 \%$ DS. In general, the detection of IL-6 occurs in studies performed during few days [40], but this inflammatory stimulus was kept for almost 1 month in the present study.

\section{CONCLUSION}

SV-loaded nanocapsules for controlled drug delivery were suitably prepared. This nanoformulation remarkable decrease the inflammation-associated collagen type III and the TNF- $\alpha$ tissue expression even at low SV dose in a chronic PD model and may be further investigated as a nanotechnology-based approach for treating peritoneal fibrosis or even EP.

We can also corroborate with Alston et al. considerations that EP is a condition related to several pathological processes that lead to the appearance of adhesion, fibrosis, vasculopathy, and the formation of encapsulated tissue on the injured peritoneal surface [43]. EP can represent a multidimensional pathological process and novel therapeutic approaches need to be proposed.

\section{AUTHORS FUNDING}

This research was funded by CNPq - Conselho Nacional de Pesquisa e Desenvolvimento, Grant number 313704/2019-8.

\section{REFERENCES}

1. United States Renal Data Systems. Available from: https://www. usrds.org/2019/view/USRDS_2019_ES_final.pdf. [Last accessed on 2020 Jan 09].

2. ERA-EDTA Registry: ERA-EDTA Registry Annual Report 2017. Amsterdam, Netherlands: Amsterdam UMC, location AMC, Department of Medical Informatics; 2019. Available from: https:// www.era-edta.org/en/registry/publications/annual-reports/\#2017.

3. Trevisani HA. Fibrosis peritoneal. Rev Nefrol Diál Trasp 2015;35:101-18.

4. Tseng $\mathrm{CC}$, Chen JB, Wang IK, Liao SC, Cheng BC, Wu AB, et al. Incidence and outcomes of encapsulating peritoneal sclerosis (EPS) and factors associated with severe EPS. PLoS One 2018;13:e190079.

5. Vidal E, Edefonti A, Puteo F, Chimenz R, Gianoglio B, Lavoratti G, et al, Italian Registry of Pediatric Chronic Dialysis. Encapsulating peritoneal sclerosis in paediatric peritoneal dialysis patients: The experience of the Italian registry of pediatric chronic dialysis. Nephrol Dial Transp 2013;28:1603-9.

6. Shroff R, Stefanidis CJ, Askiti V, Edefonti A, Testa S, Ekim M, et al, European Paediatric Dialysis Working Group. Encapsulating peritoneal sclerosis in children on chronic PD: A survey from the European paediatric dialysis working group. Nephrol Dial Transp 2013;28:1908-14.

7. Davenport A. Late presentation of encapsulating peritoneal sclerosis following renal transplantation and the potential under-reporting of the incidence and prevalence of encapsulating peritoneal sclerosis. Nephrology 2015;20:499-501.

8. Ayar Y, Ersoy A, Ocakoglu G, Gullulu E, Kagızmanlı H, Y1ldız A, et al. Encapsulating peritoneal sclerosis in peritoneal dialysis patients after kidney transplantation. Transp Proc 2018;50:160-4

9. Nitsch D, Davenport A. Designing epidemiology studies to determine the incidence and prevalence of encapsulating peritoneal sclerosis
(EPS). Perit Dial Int 2015;35:678-82

10. Ditsawanon P, Aramwit P. Preserving the peritoneal membrane in longterm peritoneal dialysis patients. J Clin Pharm Ther 2015;40:508-16.

11. Baroni G, Schuinski A, de Moraes TP, Meyer F, Pecoits-Filho R. Inflammation and the peritoneal membrane: Causes and impact on structure and function during peritoneal dialysis. Mediat Inflamm 2012;2012:912595.

12. Michos ED, McEvoy JW, Blumenthal RS. Lipid management for the prevention of atherosclerotic cardiovascular disease. N Engl J Med 2019;381:1557-67.

13. Biasucci LM, Biasillo G, Stefanelli A. Inflammatory markers, cholesterol and statins: Pathophysiological role and clinical importance. Clin Chem Lab Med 2010;48:1685-91.

14. Baroni G, Schuinski AF, Berticelli PT, Silva MA, Gouveia DS, Pecoits Filho $\mathrm{R}$, et al. The influence of simvastatin in induced peritoneal fibrosis in rats by peritoneal dialysis solution with glucosis $4.25 \%$. Acta Cir Bras 2012;27:350-6.

15. Yeniçerioglu Y, Uzelce O, Akar H, Kolatan E, Yilmaz O, Yenisey C, et al. Effects of atorvastatin on development of peritoneal fibrosis in rats on peritoneal dialysis. Ren Fail 2010;32:1095-102.

16. Chang TI, Kang HY, Kim KS, Lee SH, Nam BY, Paeng J, et al. The effect of statin on epithelial-mesenchymal transition in peritoneal mesothelial cells. PLoS One 2014;9:e109628.

17. Yang X, Yin M, Yu L, Lu M, Wang H, Tang F, et al. Simvastatin inhibited oxLDL-induced proatherogenic effects through calpain-1PPAR $\gamma$-CD36 pathway. Can J Physiol Pharmacol 2016;94:1336-43.

18. Kim EK, Cho JH, Jeong AR, Kim EJ, Park DK, Kwon KA, et al. Antiinflammatory effects of simvastatin in nonsteroidal anti-inflammatory drugs-induced small bowel injury. J Physiol Pharmacol 2017;68:69-77.

19. Kingsley JD, Dou H, Morehead J, Rabinow B, Gendelman HE, Destache CJ. Nanotechnology: A focus on nanoparticles as a drug delivery system. J Neuroimmun Pharmacol 2006;1:340-50.

20. Villanova JC, Orefice RL, Cunha AS. Aplicações farmacêuticas de polímeros. Pol Ciên Tecnol 2010;20:51-64.

21. Figueiras AR, Coimbra AB, Veiga FJ. Nanotecnologia na Saúde: Aplicação e perspectivas. Bolet Inform Geum 2014;5:14-26.

22. Murtaza G. Solubility enhancement of simvastatin: A review. Acta Pol Pharm 2012;69:581-90.

23. Rudnik LA, Farago PV, Manfron Budel J, Lyra A, Barboza FM, Klein T, et al. Co-loaded curcumin and methotrexate nanocapsules enhance cytotoxicity against non-small-cell lung cancer cells. Molecules 2020;25:1913.

24. Clementino A, Sonvico F. Development and validation of a RPHPLC method for the simultaneous detection and quantification of simvastatin's isoforms and coenzyme Q10 in lecithin/chitosan nanoparticles. J Pharm Biomed Anal 2018;155:33-41.

25. Camargo GA, Cray da Costa Filha AR, Lyra A, Novatski A, Nadal JM, Lara LS, et al. Stability testing of tacrolimus-loaded poly ( $\varepsilon$-caprolactone) nanoparticles by physicochemical assays and Raman spectroscopy. Vibration Spectrosc 2020;110:103139.

26. Mattiazzi J, Marcondes Sari MH, Brum TB, Araújo PC, Nadal JM, Farago PV, et al. 3,3'-Diindolylmethane nanoencapsulation improves its antinociceptive action: Physicochemical and behavioral studies. Colloids Surf B Biointerfaces 2019;181:295-304.

27. Gomes ML, da Silva Nascimento N, Borsato DM, Pretes AP, Nadal JM, Novatski A, et al. Long-lasting anti-platelet activity of cilostazol from poly( $\varepsilon$-caprolactone)-poly(ethylene glycol) blend nanocapsules. Mater Sci Eng C Mater Biol Appl 2019;94:694-702.

28. Gambhire M, Bhalekar M, Shrivastava B. Bioavailability assessment of simvastatin loaded solid lipid nanoparticles after oral administration. Asian J Pharm Sci 2011;6:251-8.

29. Zhang Z, Bu H, Gao Z, Huang Y, Gao F, Li Y. The characteristics and mechanism of simvastatin loaded lipid nanoparticles to increase oral bioavailability in rats. Int J Pharm 2010;394:147-53.

30. Shinde AJ, More HN. Design and evaluation of polylactic-co-glycolic acid nanoparticles containing simvastatin. Int $J$ Drug Dev Res 2011;3:280-9

31. Fathi HA, Allam A, Elsabahy M, Fetih G, El-Badry M. Nanostructured lipid carriers for improved oral delivery and prolonged antihyperlipidemic effect of simvastatin. Colloids Surf B Biointerfaces 2018;162:236-45.

32. MacDonald JS, Halleck MM. The toxicology of HMG-CoA reductase inhibitors: Prediction of human risk. Toxicol Pathol 2004;32:26-41.

33. Anbinder AL, Prado Fde A, Prado Mde A, Balducci I, Rocha RF. The influence of ovariectomy, simvastatin and sodium alendronate on alveolar bone in rats. Braz Oral Res 2007;21:247-52.

34. Claassen V. In: Huston JP, editor. Neglected Factors in Pharmacology 
and Neuroscience Research: Biopharmaceutics, Animal Characteristics Maintenance, Testing Conditions. $1^{\text {st }}$ ed. Amsterdam, Netherlands: Elsevier Science; 1995.

35. Karsdal M. Biochemistry of Collagens, Laminins and Elastin: Structure, Function and Biomarkers. $2^{\text {nd }}$ ed. Amsterdam, Netherlands: Elsevier Science; 2019.

36. Kinder JM, Then JE, Hansel PM, Molinero LL, Bruns HA. Long-term repeated daily use of intragastric gavage hinders induction of oral tolerance to ovalbumin in mice. Comp Med 2014;64:369-76.

37. Nielsen MM, Witherden DA, Havran WL. $\gamma \delta$ T cells in homeostasis and host defence of epithelial barrier tissues. Nat Rev Immunol 2017; 17:733-45

38. Mendes M, Soares HT, Arnaut LG, Sousa JJ, Pais AA, Vitorino C. Can lipid nanoparticles improve intestinal absorption? Int J Pharm 2016;515:69-83
39. Tong F, Dong B, Chai R, Tong K, Wang Y, Chen S, et al. Simvastatin nanoparticles attenuated intestinal ischemia/reperfusion injury by downregulating BMP4/COX-2 pathway in rats. Int $\mathrm{J}$ Nanomed 2017; 12:2477-88.

40. Chu F, Wang M, Ma H, Zhu J. Simvastatin modulates interaction between vascular smooth muscle cell/macrophage and TNF- $\alpha$-activated endothelial cell. J Cardiovasc Pharmacol 2018;71:268-74.

41. Kishimoto T. IL-6: From its discovery to clinical applications. Int Immunol 2010;22:347-52

42. Fielding CA, McLoughlin RM, McLeod L, Colmont CS, Najdovska M, Grail D, et al. IL-6 regulates neutrophil trafficking during acute inflammation via STAT3. J Immunol 2008;181:2189-95.

43. Alston H, Fan S, Nakayama M. Encapsulating peritoneal sclerosis. Semin Nephrol 2017;37:93-102. 